\title{
Factors associated with lifetime suicide attempts in bipolar disorder: results from an Italian nationwide study
}

\author{
Massimiliano Buoli ${ }^{1,2}$ (D) Bruno Mario Cesana ${ }^{3} \cdot$ Simone Bolognesi $^{4} \cdot$ Andrea Fagiolini $^{4} \cdot$ Umberto Albert $^{5}$. \\ Gabriele Di Salvo ${ }^{6}$. Giuseppe Maina ${ }^{6}$. Andrea de Bartolomeis ${ }^{7} \cdot$ Maurizio Pompili $^{8}$. Claudia Palumbo ${ }^{9}$. \\ Emi Bondi ${ }^{9}$. Luca Steardo $\mathrm{Jr}^{10}$. Pasquale De Fazio ${ }^{10}$. Mario Amore ${ }^{11}$. Mario Altamura ${ }^{12}$. Antonello Bellomo ${ }^{12}$. \\ Alessandro Bertolino ${ }^{13}$. Marco Di Nicola ${ }^{14,15}$. Guido Di Sciascio ${ }^{16}$. Andrea Fiorillo ${ }^{17}$. Emilio Sacchetti ${ }^{18,19}$. \\ Gabriele Sani $^{14,15}$ - Alberto Siracusano ${ }^{20,21}$. Giorgio Di Lorenzo ${ }^{20,21}$ - Alfonso Tortorella ${ }^{22}$ - A. Carlo Altamura ${ }^{1,2}$. \\ Bernardo Dell'Osso ${ }^{23,24,25}$ on behalf of the ISBD Italian Chapter Epidemiologic Group
}

Received: 23 February 2021 / Accepted: 4 October 2021 / Published online: 15 October 2021

(c) The Author(s) 2021

\begin{abstract}
The purpose of the present study was to detect demographic and clinical factors associated with lifetime suicide attempts in Bipolar Disorder (BD). A total of 1673 bipolar patients from different psychiatric departments were compared according to the lifetime presence of suicide attempts on demographic/clinical variables. Owing to the large number of variables statistically related to the dependent variable (presence of suicide attempts) at the univariate analyses, preliminary multiple logistic regression analyses were realized. A final multivariable logistic regression was then performed, considering the presence of lifetime suicide attempts as the dependent variable and statistically significant demographic/clinical characteristics as independent variables. The final multivariable logistic regression analysis showed that an earlier age at first contact with psychiatric services (odds ratio $[\mathrm{OR}]=0.97, p<0.01$ ), the presence of psychotic symptoms $(\mathrm{OR}=1.56, p<0.01)$ or hospitalizations $(\mathrm{OR}=1.73, p<0.01)$ in the last year, the attribution of symptoms to a psychiatric disorder (no versus yes: $\mathrm{OR}=0.71$, partly versus yes $\mathrm{OR}=0.60, p<0.01)$, and the administration of psychoeducation in the last year $(\mathrm{OR}=1.49$, $p<0.01)$ were all factors associated with lifetime suicide attempts in patients affected by BD. In addition, female patients resulted to have an increased association with life-long suicidal behavior compared to males (OR: 1.02, $p<0.01$ ). Several clinical factors showed complex associations with lifetime suicide attempts in bipolar patients. These patients, therefore, require strict clinical monitoring for their predisposition to a less symptom stabilization. Future research will have to investigate the best management strategies to improve the prognosis of bipolar subjects presenting suicidal behavior.
\end{abstract}

Keywords Bipolar Disorder (BD) $\cdot$ Suicidal attempts $\cdot$ Clinical features $\cdot$ Outcome

\section{Introduction}

Bipolar disorder (BD) is a widespread and severe psychiatric condition associated with reduced psychosocial functioning and a loss of life expectancy of about 10-20 years with respect to healthy general population, particularly due to suicide and cardiovascular diseases [1]. Different factors were identified as predictors of chronic course and poor outcome in $\mathrm{BD}$, including among others delayed treatment [2], lifetime presence of psychotic symptoms [3, 4], rapid cycling

Massimiliano Buoli

massimiliano.buoli@unimi.it

Extended author information available on the last page of the article
[5-7], concomitant substance misuse [8], and psychiatric/ medical comorbidity such as borderline personality disorder [9], obesity [10] or diabetes [11]. The identification of clinical predictors of illness severity allowed to a better management of $\mathrm{BD}$, and to develop targeted prevention strategies [12]. However, BD continues to be considered one of the most challenging psychiatric illnesses by clinicians in light of the high risk of suicidal behavior associated with this condition [13]. In this context, lifetime attempted suicides represent a feature worth of investigation in bipolar patients for the associated unfavorable outcomes including frequent and severe mood episodes [14].

A first prospective large-sample study identified only past history of suicide attempts as main clinical predictor of 
suicide in BD [15]. This finding was confirmed by a Swedish registry-based investigation that indicated recent affective episodes and previous self-harm as clinical aspects related to high risk of attempted suicides in BD [16]. A subsequent article reported female gender, family history for mood disorders and psychiatric comorbidity with eating disorders as factors associated with suicide attempts in bipolar patients as well as previous suicidal behavior [17], particularly when performed with violent methods [18]. An American research group found female gender, BD-I subtype, psychiatric and substance use comorbidities, lifetime history of rapid cycling, and early age at onset as clinical predictors of self-harm in a large sample of bipolar patients [19]. Previously, gender, severity of depressive symptoms and family history for depression were also reported as factors associated with suicide attempts in a sample of early-onset young bipolar subjects [20]. An Indian study, focusing on a small sample of remitted bipolar type 1 patients, found that a family history of suicide attempts was the strongest predictor of future suicidal behavior (OR: 13.65, 95\% confidence interval [CI]: 1.28-145.38) [21]. Finally, a 5-year follow-up study detected a higher risk of suicide attempts in bipolar subjects during a major depressive episode or a mixed one than in euthymia [22].

Preliminary Italian monocentric studies on small samples investigated the factors associated with suicidal behavior in BD. A first study found that a depressive polarity of first episode robustly predicted future suicide attempts in bipolar patients [23]. A subsequent investigation, focused on the clinical profile of Italian bipolar suicide attempters, reported that a number of variables such as more hospitalizations, psychiatric poly-comorbidity and depressive polarity of first episode were associated with a past history of suicide attempts [24]. The frequent depressive onset of bipolar suicide attempters may induce clinicians to prescribe antidepressants with consequent poor clinical stabilization and further risk of self-harm [25]. Finally, a very recent article reported sensitivity to weather and climate variations as important risk factors for lifetime suicide attempts in an Italian sample of bipolar patients [26].

The identification of factors associated with suicide attempts in BD can favor the implementation of prevention strategies and the prescription of a targeted pharmacotherapy [13]. In this sense, lithium should be the first choice in case of patients with suicidal ideation or attempts in the light of the well-established antisuicidal effects of this compound [27].

While studies exploring variables associated with suicide attempts in BD over the last decade have been conducted with different methodologies and limited samples, in this study, we sought to investigate, in a large multicentric sample of Italian bipolar patients, a wide series of socio-demographic and clinical features in relation with the presence of lifetime suicide attempts in BD.

\section{Methods}

A total sample of 1673 patients with BD was enrolled from different Italian psychiatric clinics in the context of the RENDiBi project (National Epidemiological Research on Bipolar Disorder). The protocol was approved by the local Ethics Committees. Patients were diagnosed as affected by BD according to DSM-IV-TR (Diagnostic and Statistical Manual of Mental Disorders) criteria [28]. Diagnoses were performed by expert psychiatrists, who had regularly monitored the interviewed patients, and confirmed by the MINI International Neuropsychiatric Interview [29, 30]. Patients consecutively presenting at outpatient or inpatient clinics were selected for the purpose of the study.

Clinical information was obtained through a review of the clinical charts and clinical interviews with patients and available relatives. Two patients were not included in the analyses of this article for the lack of information about lifetime presence of suicide attempts. A detailed list of included Italian psychiatric clinics, as well as method of calculation of sample size, was previously reported [6]. Data were registered into an electronic central database (electronic Case Report Form: e-CRF developed by Mediolanum Cardio Research, Milan, Italy).

Collected data included the following socio-demographic and clinical variables:

CLUSTER 1: socio-demographic variables: age, gender, education, employment, marital status (at least 1 lifetime marriage or partnership), living alone;

CLUSTER 2: lifetime clinical variables: BD subtype, age at onset of $\mathrm{BD}$, age at first psychopharmacological prescription (including benzodiazepines), age at first contact with psychiatric services, type of first psychiatric diagnosis, age at first psychiatric diagnosis, age at first diagnosis of $\mathrm{BD}$, age at first prescription of mood stabilizer/atypical antipsychotic, polarity of first episode, predominant polarity, duration of illness (years), DUI (years), time between age at first psychopharmacological treatment and age at first treatment for BD (years), family history of psychiatric disorders (parents), lifetime presence of psychotic symptoms, lifetime number of manic episodes, lifetime number of hypomanic episodes, lifetime number of depressive episodes, lifetime number of mixed episodes, prevalent type of cycling, lifetime presence of medical comorbidity, lifetime presence of psychiatric comorbidity, lifetime more effective therapy;

CLUSTER 3: clinical variables-last year of observation: presence of manic episodes, presence of depressive 
episodes, presence of hypomanic episodes, presence of mixed episodes, presence of psychotic symptoms, comorbidity with substance misuse, presence of hospitalizations, presence of insight, attribution of symptoms to a psychiatric disorder, treatment adherence, number of visits, time between visits for euthymic patients (days),current administration of psychotherapy, administration of psychoeducational interventions (according to Colom's model) [31].

Duration of untreated illness was considered as the time elapsing between first episode of BD and the prescription of a proper pharmacological treatment (mood stabilizer or atypical antipsychotic with stabilizing effects) [2]. Predominant polarity was calculated according to the Barcelona proposal, defined as at least two-thirds (2/3) of the total number of past episodes being from the same polarity [32]. The presence of psychotic symptoms refers to all types of major mood episodes (manic, mixed or depressive ones). The variable "attribution of symptoms to a psychiatric disorder" refers to patients denying fully or partially that their symptoms belong to a psychiatric condition, differentiating from "insight" that was defined as the awareness to have symptoms.

Suicide attempt was defined as self-harm combined with the intent to die. Self-harm without intent was not taken into account. Similarly to the other variables, the information about suicide attempts was obtained through a review of the clinical charts and clinical interviews with patients and available relatives and registered into the e-CRF.

Exclusion criteria included: (1) patients who had not been screened in the last 12 months making it impossible to collect data for the last year of observation) and (2) patients whose clinical information was incomplete.

Descriptive analyses of the total sample were performed. The total sample was then divided in two groups according to the presence of lifetime suicide attempts. The two groups were compared for the above mentioned variables by $t$ tests for quantitative variables and Chi square tests for qualitative ones.

Owing to the large number of variables statistically related to the dependent variable (the presence of lifetime suicide attempts) at the univariate analyses, preliminary multiple logistic regression analyses (for each of the above mentioned clusters) were performed including only statistically significant variables. In the model, we included also age, despite being non-significant in the univariate analyses, being the younger and the older individuals more prone to impulsivity and suicidal behaviors [33]. Finally, statistically significant variables from these final models were inserted in a new global multivariable logistic regression model (adjusted for gender) to obtain the variables independently associated with the presence of lifetime suicide attempts.
The choice to adjust the final model for gender was due to the fact that another analysis on the sample showed demographic and clinical differences according to this variable [34].

The selection of the variables was done according to a backward procedure; the goodness of fitting was assessed by the Hosmer-Lemeshow test.

The level of statistical significance was set at $p \leq 0.05$. Statistical analyses were performed by $\mathrm{SAS}^{\circledR} 9.2$ version.

\section{Results}

The total sample included 1673 patients: 714 males (42.7\%) and 959 females (57.3\%). Four hundred and forty patients ( $26.3 \%$ of the total sample) reported at least one lifetime suicide attempts. At the moment of the assessment, 242 subjects were experiencing a major depressive episode (14.4\%), $198(11.9 \%)$ mania, $26(1.6 \%)$ hypomania, $150(9.0 \%)$ a mixed episode, and 1057 (63.1\%) were euthymic.

Descriptive analyses of the total sample and groups divided according to the lifetime presence of suicide attempts are reported in Tables 1, 2, 3 .

There were no significant differences between groups identified by the lifetime presence of suicide attempts in terms of age $(p=0.37)$, employment $(p=0.17)$ and living alone status $(p=0.26)$, time between the first treatment for $\mathrm{BD}$ and first psychiatric treatment $(\mathrm{p}=0.06)$, duration of untreated illness $(p=0.36)$, lifetime number of manic episodes $(p=0.13)$, lifetime number of hypomanic episodes $(p=0.55)$, family history for psychiatric disorders (mothers) $(p=0.36)$, type of lifetime more effective therapy $(p=0.16)$, lifetime medical comorbidity ( $p=0.45$ ), prevalent type of cycling $(p=0.59)$, presence of hypomanic $(p=0.58)$ and manic $(p=0.60)$ episodes in the last year of observation, treatment adherence $(p=0.81)$, number of days between visits when patients are euthymic $(p=0.10)$, substance misuse in the last year of observation $(p=0.88)$, current administration of psychotherapy $(p=0.17)$.

On the other hand, subjects with lifetime suicide attempts resulted: to be more frequently women $(p<0.01)$, less educated $(p=0.02)$, to have had at least one lifetime marriage or partnership $(p=0.02)$, to have an earlier age at onset $(p<0.01)$, to have an earlier age at first pharmacological prescription $(p<0.01)$, to have an earlier age at first contact with psychiatric services $(p<0.01)$, to have an earlier age at first psychiatric diagnosis $(p<0.01)$, to have an earlier age at first diagnosis of $\mathrm{BD}(p=0.03)$, to have an earlier age at first mood stabilizer or atypical antipsychotic prescription $(p=0.03)$, to have received more frequently a first diagnosis different from BD (in most of cases of a Major Depressive Disorder) $(p<0.01)$, to have a longer duration of illness $(p<0.01)$, to more frequently show depressive polarity of 
Table 1 Socio-demographic variables of the total sample and of the two groups obtained according to the presence of lifetime suicide attempts

\begin{tabular}{llccc}
\hline Variables & & Total sample $N=1673$ & $\begin{array}{l}\text { Absence of lifetime suicide } \\
\text { attempts } N=1233(73.7 \%)\end{array}$ & $\begin{array}{l}\text { Presence of lifetime suicide } \\
\text { attempts } N=440(26.3 \%)\end{array}$ \\
\hline Gender Missing: $n=0$ & Male & $714(42.7 \%)$ & $553(44.9 \%)$ & $161(36.6 \%)$ \\
& Female & $959(57.3 \%)$ & $680(55.1 \%)$ & $279(63.4 \%)$ \\
Education (years) Missing: $n=5$ & $<13$ & $603(36.1 \%)$ & $436(35.4 \%)$ & $167(38.1 \%)$ \\
& $<16$ & $749(44.9 \%)$ & $541(44.0 \%)$ & $208(47.5 \%)$ \\
& $\geq 16$ & $316(19.0 \%)$ & $253(20.6 \%)$ & $63(14.4 \%)$ \\
Employed missing: $n=3$ & Yes & $1264(75.7 \%)$ & $943(76.5 \%)$ & $321(73.3 \%)$ \\
& No & $406(24.3 \%)$ & $289(23.5 \%)$ & $117(26.7 \%)$ \\
Marriage or partnership missing: $n=2$ & $\geq 1$ & $1138(68.1 \%)$ & $820(66.6 \%)$ & $318(72.4 \%)$ \\
& Never & $533(31.9 \%)$ & $412(33.4 \%)$ & $121(27.6 \%)$ \\
Living alone missing: $n=2$ & Yes & $287(17.2 \%)$ & $204(16.6 \%)$ & $83(18.9 \%)$ \\
Age missing: $n=0$ & No & $1384(82.8 \%)$ & $1028(83.4 \%)$ & $356(81.1 \%)$ \\
\hline
\end{tabular}

Standard deviations for the variable "age" and percentages for qualitative variables are reported into brackets In bold statistically significant $\mathrm{p}$ resulting from $\chi^{2}$ and from unpaired Student's $t$ test for the variable "age"

first episode $(p<0.01)$ and depressive predominant polarity $(\mathrm{p}<0.01)$, to present a higher lifetime number of depressive episodes $(p<0.01)$, to present more lifetime mixed episodes $(p<0.01)$, to show a more frequent paternal family history of $\mathrm{BD}(p=0.01)$, to have a diagnosis of BD type $1(\mathrm{p}<0.01)$, to present more frequent lifetime psychotic symptoms $(p<0.01)$ and psychiatric comorbidity $(p=0.03)$, to have a higher number of depressive $(p<0.01)$ and mixed episodes $(p<0.01)$ in the last year, to have more insight $(p=0.05)$, to more frequently attribute symptoms to a psychiatric disorder $(p<0.01)$, to have more frequently received psychoeducation in the last year $(p=0.01)$, to have more hospitalizations in the last year $(p<0.01)$, to present more psychotic symptoms in the last year $(p<0.01)$, to have had more visits in the last year $(p<0.01)$.

The results of the goodness-of-fit test (Hosmer and Lemeshow Test: $\chi^{2}=5.14, \mathrm{df}=8, p=0.74$ ) showed that final multivariable logistic regression model including socio-demographic/clinical variables as possible associated factors of the lifetime presence of suicide attempts (adjusted for gender) was reliable. Of note, bipolar patients with versus without lifetime presence of suicide attempts resulted to be older (odds ratio-OR $=1.02, p<0.01$ ), to have an earlier age at first contact with psychiatric services $(\mathrm{OR}=0.97, p<0.01)$, to present more frequently psychotic symptoms in the last year $(\mathrm{OR}=1.56, p<0.01)$, to present more frequently hospitalizations in the last year $(\mathrm{OR}=1.73, p<0.01)$, to attribute more frequently the symptoms to a psychiatric disorder (no versus yes: $\mathrm{OR}=0.71$, partly versus yes $\mathrm{OR}=0.60$, $p<0.01$ ), to have received more frequently psychoeducation in the last year $(\mathrm{OR}=1.49, p<0.01)$, and finally to have had more visits at a borderline statistical significance $(\mathrm{OR}=1.01$, $p=0.06$ ) (Table 4).
In addition, removing from the above multivariable model the variables psychoeducation in the last year, number of hospitalizations, and number of visits, in the light of their not unique temporal relationship with the lifetime presence of suicide attempts leading to a controversial interpretation of their role, bipolar patients with versus without lifetime presence of suicide attempts resulted to be older $(\mathrm{OR}=1.02$, $p<0.01$ ), to have an earlier age at first contact with psychiatric services $(\mathrm{OR}=0.97, p<0.01)$, to present more frequently psychotic symptoms in the last year $(\mathrm{OR}=1.84, p<0.01)$, to attribute more frequently the symptoms to a psychiatric disorders (no versus yes: $\mathrm{OR}=0.65$, partly versus yes $\mathrm{OR}=0.60, p<0.01)$. The results of the goodness-of-fit test (Hosmer and LemeshowTest: $\chi^{2}=3.52, \mathrm{df}=8, p=0.59$ ) showed that this multivariable logistic regression model, adjusted for gender (female versus male $\mathrm{OR}=1.23, p=0.08$ ) was reliable.

Finally, if in the multivariable logistic model we insert only the variables that are supposed to precede or to be independent from the first lifetime suicide attempt, the ORs $(95 \%$ confidence interval-CI) result to be 1.28 (CI:1.02-1.61, $p=0.03$ ) for gender (female versus male) and 0.97 (CI: $0.96-0.98, p<0.01$ ) for each unit increase of age at first contact with psychiatric services. Therefore, an earlier age at first contact with psychiatric services is confirmed as a factor associated with lifetime suicide attempts, but in this case also female gender resulted to be significantly related with suicidal behaviors. The above estimates and significance remain practically unchanged if we add in the model the variable age (1.02 for each unit increase: CI:1.01-1.03, $p<0.01$ ) for having the odds ratios adjusted for. 


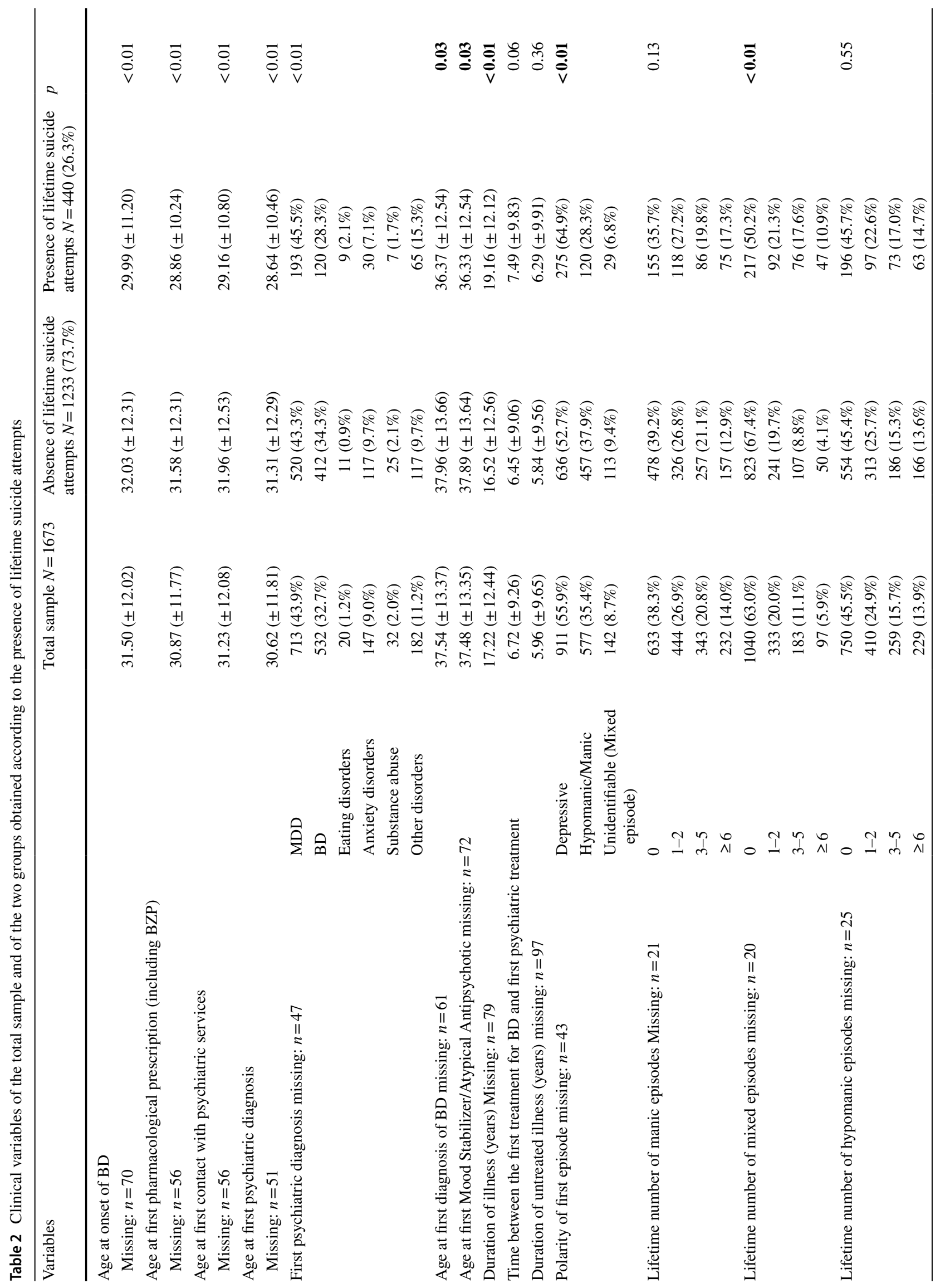




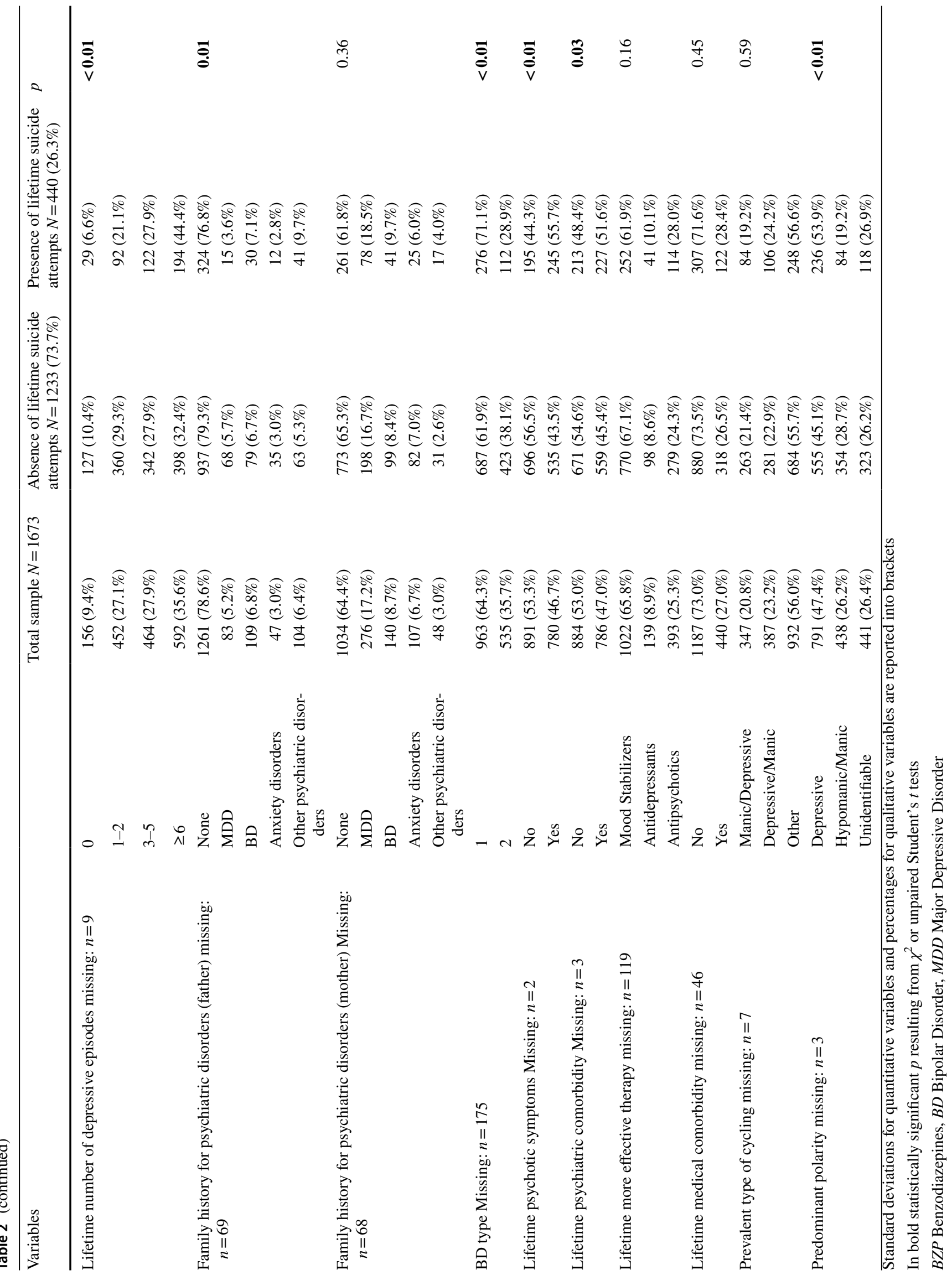


Table 3 Clinical variables of the total sample and of the two groups obtained according to the presence of lifetime suicide attempts (last year of observation)

\begin{tabular}{|c|c|c|c|c|c|}
\hline \multicolumn{2}{|l|}{ Variables } & \multirow{2}{*}{$\begin{array}{l}\text { Total Sample } N=1673 \\
1262(75.6 \%)\end{array}$} & \multirow{2}{*}{$\begin{array}{l}\text { Absence of Lifetime Suicide } \\
\text { Attempts } N=1233(73.7 \%) \\
958(77.8 \%)\end{array}$} & \multirow{2}{*}{$\begin{array}{l}\text { Presence of Lifetime } \\
\text { Suicide Attempts } N=440 \\
(26.3 \%)\end{array}$} & \multirow{2}{*}{$\begin{array}{l}p \\
<\mathbf{0 . 0 1}\end{array}$} \\
\hline Presence of psychotic symptoms missing: & No & & & & \\
\hline$n=4$ & Yes & $407(24.4 \%)$ & $272(22.1 \%)$ & $135(30.7 \%)$ & \\
\hline \multirow[t]{2}{*}{ Presence of hospitalizations missing: $n=0$} & No & $987(59.0 \%)$ & $777(63.0 \%)$ & $210(47.7 \%)$ & $<0.01$ \\
\hline & Yes & $686(41.0 \%)$ & $456(37.0 \%)$ & $230(52.3 \%)$ & \\
\hline \multirow{2}{*}{$\begin{array}{l}\text { Presence of depressive episodes missing: } \\
n=98\end{array}$} & No & $865(54.9 \%)$ & $666(57.2 \%)$ & $199(48.4 \%)$ & $<0.01$ \\
\hline & Yes & $710(45.1 \%)$ & $498(42.8 \%)$ & $212(51.6 \%)$ & \\
\hline \multirow{2}{*}{$\begin{array}{l}\text { Presence of mixed episodes missing: } \\
\quad n=97\end{array}$} & No & $1317(83.6 \%)$ & $990(85.0 \%)$ & $327(79.4 \%)$ & $<0.01$ \\
\hline & Yes & $259(16.4 \%)$ & $174(15.0 \%)$ & $85(20.6 \%)$ & \\
\hline \multirow{2}{*}{$\begin{array}{l}\text { Presence of hypomanic episodes missing: } \\
\quad n=116\end{array}$} & No & $1253(80.5 \%)$ & $920(80.1 \%)$ & $333(81.4 \%)$ & 0.58 \\
\hline & Yes & $304(19.5 \%)$ & $228(19.9 \%)$ & $76(18.6 \%)$ & \\
\hline \multirow{2}{*}{$\begin{array}{l}\text { Presence of manic episodes missing: } \\
n=91\end{array}$} & No & $1266(80 \%)$ & $931(79.7 \%)$ & $335(80.9 \%)$ & 0.60 \\
\hline & Yes & $316(20.0 \%)$ & $237(20.3 \%)$ & $79(19.1 \%)$ & \\
\hline \multirow[t]{3}{*}{ Insight missing: $n=2$} & No & $78(4.7 \%)$ & $60(4.9 \%)$ & $18(4.1 \%)$ & 0.05 \\
\hline & Yes & $1165(69.7)$ & $839(68.1 \%)$ & $326(74.3 \%)$ & \\
\hline & Partial & $428(25.6 \%)$ & $333(27.0 \%)$ & $95(21.6 \%)$ & \\
\hline \multirow{3}{*}{$\begin{array}{l}\text { Attribution of symptoms to a psychiatric } \\
\text { disorder missing: } n=3\end{array}$} & No & $131(7.8 \%)$ & $99(8.0 \%)$ & $32(7.3 \%)$ & $<0.01$ \\
\hline & Yes & $1064(63.7 \%)$ & $758(61.6 \%)$ & $306(69.7 \%)$ & \\
\hline & Partial & $475(28.5 \%)$ & $374(30.4 \%)$ & $101(23.0 \%)$ & \\
\hline \multirow[t]{3}{*}{ Treatment adherence missing: $n=7$} & No & $124(7.4 \%)$ & $89(7.2 \%)$ & $35(8.0 \%)$ & 0.81 \\
\hline & Yes & $1156(69.4 \%)$ & $850(69.3 \%)$ & $306(69.7 \%)$ & \\
\hline & Partial & $386(23.2 \%)$ & $288(23.5 \%)$ & $98(22.3 \%)$ & \\
\hline \multicolumn{2}{|l|}{ Number of visits missing: $n=103$} & $9.67( \pm 9.07)$ & $9.22( \pm 8.62)$ & $10.95( \pm 11.94)$ & $<0.01$ \\
\hline \multicolumn{2}{|c|}{$\begin{array}{l}\text { Number of days between visits when patients are } \\
\text { in euthymia missing: } n=178\end{array}$} & $46.63( \pm 40.28)$ & $47.65( \pm 40.04)$ & $43.72( \pm 40.94)$ & 0.10 \\
\hline \multirow[t]{2}{*}{ Psychoeducation missing: $n=8$} & No & $1394(83.7 \%)$ & $1044(85.1 \%)$ & $350(79.9 \%)$ & 0.01 \\
\hline & Yes & $271(16.3 \%)$ & $183(14.9 \%)$ & $88(20.1 \%)$ & \\
\hline \multirow[t]{2}{*}{ Substance misuse missing: $n=1$} & No & $1471(88.0 \%)$ & $1083(87.9 \%)$ & $388(88.2 \%)$ & 0.88 \\
\hline & Yes & $201(12.0 \%)$ & $149(12.1 \%)$ & $52(11.2 \%)$ & \\
\hline \multirow[t]{2}{*}{ Current psychotherapy missing: $n=5$} & No & $1423(85.3 \%)$ & $1058(86.0 \%)$ & $365(83.3 \%)$ & 0.17 \\
\hline & Yes & $245(14.7 \%)$ & $172(14.0 \%)$ & $73(16.7 \%)$ & \\
\hline
\end{tabular}

Standard deviations for quantitative variables and percentages for qualitative variables are reported into brackets

In bold statistically significant results from $\chi^{2}$ or unpaired Student's $t$ tests

\section{Discussion}

To authors' knowledge, this is the first multicenter study conducted in Italy with a large sample of bipolar patients, with the aim to assess a large set of variables in relation to lifetime suicide attempts. About $26 \%$ of the total sample reported at least one lifetime suicidal attempts. This figure is lower with respect to that reported by other studies [35] and this aspect can be explained by differences in treatment in our patients in comparison to other reported case series and by the fact that some of our patients were followed in tertiary care clinics.

Lifetime presence of suicide attempts resulted to be associated with a number of demographic and clinical variables, including a lower level of education, the presence of a lifetime marriage/partnership, female gender, an earlier age at onset, a first psychiatric misdiagnosis with a Major Depressive Disorder, a longer duration of illness, a depressive polarity of first mood episode, lifetime number of mixed/depressive episodes, paternal family history of $\mathrm{BD}, \mathrm{BD}$ type 1 , lifetime psychiatric comorbidity, depressive predominant polarity, recent depressive/mixed episodes, presence of insight. In addition, even a more robust association, as shown by the final multivariable logistic regression model, was found between the lifetime presence of suicidal behavior in bipolar patients and an earlier age at first contact with psychiatric services, last year presence of hospitalizations and psychotic symptoms, recent administration of 
Table 4 Summary of the statistics for the best-fit multivariable logistic regression model applied

\begin{tabular}{lllrr}
\hline Variables & Categories & Odds Ratio & 95\%CI & $p$ \\
\hline Age & NA & 1.02 & $1.01-1.03$ & $<\mathbf{0 . 0 1}$ \\
Gender & Female vs male & 1.20 & $0.95-1.53$ & 0.15 \\
Age at first contact with psychiatric services & NA & 0.97 & $0.96-0.99$ & $<\mathbf{0 . 0 1}$ \\
Presence of psychotic symptoms in the last year & Yes vs. no & 1.45 & $1.01-1.92$ & $<\mathbf{0 . 0 1}$ \\
Presence of hospitalizations in the last year & Yes vs. no & 1.73 & $1.35-2.22$ & $<\mathbf{0 . 0 1}$ \\
Attribution of symptoms to a psychiatric disorder & No vs. yes & 0.71 & $0.44-1.17$ & $<\mathbf{0 . 0 1}$ \\
& Partial vs. yes & 0.60 & $0.45-0.80$ & \\
Administration of psychoeducation in the last year & No vs. yes & 0.67 & $0.50-0.90$ & $<\mathbf{0 . 0 1}$ \\
Number of visits in the last year & NA & 1.01 & $0.99-1.02$ & 0.06 \\
\hline
\end{tabular}

In this analysis, the dependent variable was lifetime presence of suicidal attempts. With regard to age and number of visits, the odds ratio means the increase of the association for each unit of year or visit increase. However, OR is 1.09 (95\% CI: 1.04-1.15), 1.19 (95\% CI: 1.07-1.32), 1.30 (95\% CI: 1.14-1.52) for 5, 10 and 15 years increase, respectively. Furthermore, OR is 1.02 (95\% CI: 0.99-1.05), 1.04 (95\% CI: 0.991.07), 1.05 (95\% CI: $0.99-1.10)$ for 2,3 and 4 visit increase, respectively

Hosmer-Lemeshow test: $\chi^{2}=5.14, \mathrm{df}=8, p=0.74$

$V s=$ versus $N A=$ not applicable $95 \% C I=95 \%$ Confidence Interval

In bold statistically significant $p$ values psychoeducation, attribution of symptoms to a psychiatric disorder and number of visits in the last year at a borderline statistically significant level. Finally, the multivariable logistic regression model including only the factors supposed to precede or to be independent from the first lifetime suicide attempt show a relation of an earlier age at first contact with psychiatric services and female gender with suicidal behaviors. While some of these findings confirm results of previous reports, other results are mostly unprecedented.

The level of education has been poorly investigated in terms of suicidal behaviors in patients with BD. A recent article reported that a higher level of education was more frequent in subjects with BD type 2 [36] that in turn, accordingly to our data, seemed be less associated with a lifetime risk of suicide attempts. With regard to marital status, our findings seem to contradict previous literature revealing that people who are single or divorced present a greater vulnerability to suicide [7]. These opposite results can be explained by the different way to classify marital status in our dataset (considering lifetime marriages/partnerships) than the previous published articles about this topic [13]. Of note, the variable "lifetime marriages" includes separated or divorced individuals who might have experienced more unstable relationships. Our data confirmed that female gender remains one of the factors associated with lifetime suicide attempts in $\mathrm{BD}$ in agreement with several previous studies [17, 19, 20].

With regard to clinical variables, the results of the present study confirm the findings from previous studies, specifically showing that suicidal behavior in BD is predicted by a number of variables associated with a more severe course of illness, such as an early age at onset [37], a longer duration of illness [38], family history of BD [17] or the presence of psychiatric comorbidity $[17,19,37]$.
As confirmed by our data in agreement with previous literature, depressive symptoms, namely recent/lifetime depressive episodes [16] and predominant depressive polarity, seem to have a prominent role in conferring vulnerability to suicide attempts in bipolar patients $[15,20]$. Similarly, the presence of mixed symptoms, likely associated with higher levels of impulsivity, was found to be predictive of suicidal behavior in BD in several reports [22] as well as in our study. As highlighted in previous studies by our [2, 3] and other research groups [39], a depressive polarity of the first episode in bipolar patients with higher risk of suicide attempts [23] may favor misdiagnosis of these subjects who, treated with antidepressant mono-therapy, can show a worse prognosis in terms of inadequate clinical stabilization, greater impulsivity and occurrence of suicide attempts [25, 40].

Data about the association of bipolar subtype and presence of suicidal behavior are more difficult to interpret with studies reporting a relation with BD type 2 [18] and others that, in agreement with our findings, detected more propensity to suicide attempts in bipolar 1 patients [19]. This contradiction is not totally surprising as other factors such as depressive symptoms, more prevalent in the longitudinal course of BD type 2, may contribute to the vulnerability to suicidal behavior. Nonetheless, also bipolar type 1 patients spend most of their illness in depression that is one of the main predictors of suicidal attempts [41]. Ultimately, complex associations of different variables concur to confer a higher risk of suicide attempts across bipolar subtypes, including also cultural and geographical aspects [42] and specific patterns of comorbidity [43].

Of note, our results detected a larger amount of insight in patients with lifetime suicide attempts contradicting the results of previous research articles [44]. This finding can be 
explained by the fact that our patients with suicide attempts also received more psychoeducation than those without previous suicide attempts. Another possible reason is that suicide attempts occur more frequently in patients with depressive polarity or with recent depressive episodes that usually are characterized by more insight with respect to mania [45]. Finally, a relatively recent study [46] found that not only the lack, but also the change of insight is associated with suicidal behaviors in patients affected by severe mental disorders such as BD where the different mood phases are characterized by variable insight. In support of the mentioned hypotheses, recent research highlighted that insight coupled with depression may be associated to an increased suicidal risk in patients affected by severe mental conditions [47].

Finally, the results of the present study clearly indicate that patients with lifetime suicide attempts present less clinical stability in terms of more recent hospitalizations, psychotic symptoms and number of visits, therefore requiring a more strict follow-up and an integrated therapy (e.g., with pharmacotherapy and psychoeducation) [48]. Future research will have to investigate the best management strategies to improve the prognosis of bipolar subjects presenting suicidal behavior, eventually differentiating between single versus multiple suicide attempters.

The abovementioned results need to be interpreted in light of the following limitations:

(1) patients were treated with different drugs which might have influenced some clinical features (e.g., the prescription of first generation antipsychotics during mania favoring the switch to depression);

(2) the different settings of care (in several Italian regions) may have influenced the clinical features of the sample (e.g., the availability of psychoeducation or of targeted day hospital units for mood disorders);

(3) even though some of the patients were selected in community primary care services, others have been treated in tertiary academic care units, with a potentially differential influence of the setting over some clinical features (e.g., more severe patients are usually treated in secondary or tertiary care units);

(4) some data were collected retrospectively (e.g., number of mood episodes, past attempted suicides) so that they might have not been always as accurate as in controlled studies;

(5) the lack of a follow-up period due to the cross-sectional nature of the study that limits any causal inference;

(6) the impossibility to perform an analysis considering single versus multiple suicide attempters.

Finally, the findings presented in this article have not to be interpreted in the terms of causal inference, but only as the associations between the independent variables and the event, given for granted their possible role as confounders, as it should be highlighted for all the multivariable models fitted in the biomedical observational research.

Acknowledgements The authors thank all the centers and the collaborators (clinicians and residents) that have contributed to sample recruitment, including among others Prof. Arianna Goracci, Dr. Alessandro Cuomo, Dr. Edwige Cuozzo, Dr. Angelo Rinaldi, Dr. Gregorio Cerminara.

Author contributions $\mathrm{MB}$ wrote the paper. BMC performed the statistical analyses and revised the manuscript. BD revised the manuscript and contributed substantially to the final version of the text. All the other authors revised the manuscript and contributed to the sample collection.

Funding Open access funding provided by Università degli Studi di Milano within the CRUI-CARE Agreement.

\section{Declarations}

Conflict of interest The authors have not conflicts of interest to disclose in relation to the present article.

Ethical approval This study was performed in line with the principles of 1964 Helsinki Declaration. All procedures have been approved by the Institutional Review Boards.

Open Access This article is licensed under a Creative Commons Attribution 4.0 International License, which permits use, sharing, adaptation, distribution and reproduction in any medium or format, as long as you give appropriate credit to the original author(s) and the source, provide a link to the Creative Commons licence, and indicate if changes were made. The images or other third party material in this article are included in the article's Creative Commons licence, unless indicated otherwise in a credit line to the material. If material is not included in the article's Creative Commons licence and your intended use is not permitted by statutory regulation or exceeds the permitted use, you will need to obtain permission directly from the copyright holder. To view a copy of this licence, visit http://creativecommons.org/licenses/by/4.0/.

\section{References}

1. McIntyre RS, Berk M, Brietzke E, Goldstein BI, López-Jaramillo C, Kessing LV, Malhi GS, Nierenberg AA, Rosenblat JD, Majeed A, Vieta E, Vinberg M, Young AH, Mansur RB (2020) Bipolar disorders. Lancet 396(10265):1841-1856. https://doi.org/10.1016/ S0140-6736(20)31544-0

2. Buoli M, Cesana BM, Fagiolini A, Albert U, Maina G, de Bartolomeis A, Pompili M, Bondi E, Steardo L Jr, Amore M, Bellomo A, Bertolino A, Di Nicola M, Di Sciascio G, Fiorillo A, Rocca P, Sacchetti E, Sani G, Siracusano A, Di Lorenzo G, Tortorella A, Altamura AC, Dell'Osso B; ISBD Italian Chapter Epidemiologic Group (2020) Which factors delay treatment in bipolar disorder? A nationwide study focussed on duration of untreated illness. Early Interv Psychiatry. https://doi.org/10.1111/eip.13051

3. Altamura AC, Buoli M, Caldiroli A, Caron L, Cumerlato Melter C, Dobrea C, Cigliobianco M, Zanelli Quarantini F (2015) Misdiagnosis, duration of untreated illness (DUI) and outcome in bipolar patients with psychotic symptoms: a naturalistic study. J 
Affect Disord 182:70-75. https://doi.org/10.1016/j.jad.2015.04. 024

4. Sheffield JM, Karcher NR, Barch DM (2018) Cognitive deficits in psychotic disorders: a lifespan perspective. Neuropsychol Rev 28(4):509-533. https://doi.org/10.1007/s11065-018-9388-2

5. Cruz N, Vieta E, Comes M, Haro JM, Reed C, Bertsch J, Advisory Board EMBLEM (2008) Rapid-cycling bipolar I disorder: course and treatment outcome of a large sample across Europe. J Psychiatr Res 42(13):1068-1075. https://doi.org/10.1016/j.jpsyc hires. 2007

6. Buoli M, Cesana BM, Maina G, Conca A, Fagiolini A, Steardo L Jr, Altamura AC, Dell'Osso B; ISBD Italian Chapter Epidemiologic Group (2019) Correlates of current rapid-cycling bipolar disorder: Results from the Italian multicentric RENDiBi study. Eur Psychiatry 62:82-89. https://doi.org/10.1016/j.eurpsy.2019. 09.001

7. Schaffer A, Isometsä ET, Azorin JM, Cassidy F, Goldstein T, Rihmer Z, Sinyor M, Tondo L, Moreno DH, Turecki G, Reis C, Kessing LV, Ha K, Weizman A, Beautrais A, Chou YH, Diazgranados N, Levitt AJ, Zarate CA Jr, Yatham L (2015) A review of factors associated with greater likelihood of suicide attempts and suicide deaths in bipolar disorder: Part II of a report of the International Society for Bipolar Disorders Task Force on Suicide in Bipolar Disorder. Aust N Z J Psychiatry 49(11):1006-20. https://doi.org/ 10.1177/0004867415594428.

8. Messer T, Lammers G, Müller-Siecheneder F, Schmidt RF, Latifi S (2017) Substance abuse in patients with bipolar disorder: a systematic review and meta-analysis. Psychiatry Res 253:338-350. https://doi.org/10.1016/j.psychres.2017.02.067

9. Post RM, Leverich GS, McElroy S, Kupka R, Suppes T, Altshuler L, Nolen W, Frye M, Keck P, Grunze H, Rowe M (2020) Relationship of comorbid personality disorders to prospective outcome in bipolar disorder. J Affect Disord 276:147-151. https://doi.org/10. 1016/j.jad.2020.07.031

10. Buoli M, Dell'Osso B, Caldiroli A, Carnevali GS, Serati M, Suppes T, Ketter TA, Altamura AC (2017) Obesity and obstetric complications are associated with rapid-cycling in Italian patients with bipolar disorder. J Affect Disord 208:278-283. https://doi.org/10. 1016/j.jad.2016.10.010

11. Charles EF, Lambert CG, Kerner B (2016) Bipolar disorder and diabetes mellitus: evidence for disease-modifying effects and treatment implications. Int J Bipolar Disord 4(1):13. https://doi. org/10.1186/s40345-016-0054-4

12. Perugi G, De Rossi P, Fagiolini A, Girardi P, Maina G, Sani G, Serretti A (2019) Personalized and precision medicine as informants for treatment management of bipolar disorder. Int Clin Psychopharmacol 34(4):189-205. https://doi.org/10.1097/YIC.00000 00000000260

13. Miller JN, Black DW (2020) Bipolar disorder and suicide: a review. Curr Psychiatry Rep 22(2):6. https://doi.org/10.1007/ s11920-020-1130-0

14. Hawton K, Sutton L, Haw C, Sinclair J, Harriss L (2005) Suicide and attempted suicide in bipolar disorder: a systematic review of risk factors. J Clin Psychiatry 66(6):693-704. https://doi.org/10. 4088/jcp.v66n0604

15. Marangell LB, Bauer MS, Dennehy EB, Wisniewski SR, Allen MH, Miklowitz DJ, Oquendo MA, Frank E, Perlis RH, Martinez JM, Fagiolini A, Otto MW, Chessick CA, Zboyan HA, Miyahara S, Sachs G, Thase ME (2006) Prospective predictors of suicide and suicide attempts in 1,556 patients with bipolar disorders followed for up to 2 years. Bipolar Disord 8(5 Pt 2):566-575. https:// doi.org/10.1111/j.1399-5618.2006.00369.x

16. Tidemalm D, Haglund A, Karanti A, Landén M, Runeson B (2014) Attempted suicide in bipolar disorder: risk factors in a cohort of 6086 patients. PLoS ONE 9(4):e94097. https://doi.org/ 10.1371/journal.pone.0094097
17. Berkol TD, İslam S, Kırlı E, Pınarbaşı R, Özyıldırım İ (2016) Suicide attempts and clinical features of bipolar patients. Saudi Med J 37(6):662-667. https://doi.org/10.15537/Smj.2016.6.12776

18. Plans L, Nieto E, Benabarre A, Vieta E (2019) Completed suicide in bipolar disorder patients: A cohort study after first hospitalization. J Affect Disord 257:340-344. https://doi.org/10.1016/j.jad. 2019.07.048

19. Bobo WV, Na PJ, Geske JR, McElroy SL, Frye MA, Biernacka JM (2018) The relative influence of individual risk factors for attempted suicide in patients with bipolar I versus bipolar II disorder. J Affect Disord 225:489-494. https://doi.org/10.1016/j.jad. 2017.08.076

20. Goldstein TR, Ha W, Axelson DA, Goldstein BI, Liao F, Gill MK, Ryan ND, Yen S, Hunt J, Hower H, Keller M, Strober M, Birmaher B (2012) Predictors of prospectively examined suicide attempts among youth with bipolar disorder. Arch Gen Psychiatry 69(11):1113-1122. https://doi.org/10.1001/archgenpsychiat ry. 2012.650

21. Subramanian K, Menon V, Sarkar S, Chandrasekaran V, Selvakumar N (2020) Study of risk factors associated with suicide attempt in patients with bipolar disorder type I. J Neurosci Rural Pract 11(2):291-298. https://doi.org/10.1055/s-0040-1709347

22. Pallaskorpi S, Suominen K, Ketokivi M, Valtonen H, Arvilommi P, Mantere O, Leppämäki S, Isometsä E (2017) Incidence and predictors of suicide attempts in bipolar I and II disorders: A 5-year follow-up study. Bipolar Disord 19(1):13-22. https://doi.org/10. 1111/bdi.12464

23. Cremaschi L, Dell'Osso B, Vismara M, Dobrea C, Buoli M, Ketter TA, Altamura AC (2017) Onset polarity in bipolar disorder: A strong association between first depressive episode and suicide attempts. J Affect Disord 209:182-187. https://doi.org/10.1016/j. jad.2016.11.043

24. Dell'Osso B, Vismara M, Dobrea C, Cremaschi L, Grancini B, Arici C, Benatti B, Buoli M, Ketter TA, Altamura AC (2018) Clinical characterization of Italian suicide attempters with bipolar disorder. CNS Spectr 23(4):271-277. https://doi.org/10.1017/ S1092852917000384

25. Pacchiarotti I, Bond DJ, Baldessarini RJ, Nolen WA, Grunze H, Licht RW, Post RM, Berk M, Goodwin GM, Sachs GS, Tondo L, Findling RL, Youngstrom EA, Tohen M, Undurraga J, GonzálezPinto A, Goldberg JF, Yildiz A, Altshuler LL, Calabrese JR, Mitchell PB, Thase ME, Koukopoulos A, Colom F, Frye MA, Malhi GS, Fountoulakis KN, Vázquez G, Perlis RH, Ketter TA, Cassidy F, Akiskal H, Azorin JM, Valentí M, Mazzei DH, Lafer B, Kato T, Mazzarini L, Martínez-Aran A, Parker G, Souery D, Ozerdem A, McElroy SL, Girardi P, Bauer M, Yatham LN, Zarate CA, Nierenberg AA, Birmaher B, Kanba S, El-Mallakh RS, Serretti A, Rihmer Z, Young AH, Kotzalidis GD, MacQueen GM, Bowden CL, Ghaemi SN, Lopez-Jaramillo C, Rybakowski J, Ha K, Perugi G, Kasper S, Amsterdam JD, Hirschfeld RM, Kapczinski F, Vieta E (2013) The international society for bipolar disorders (isbd) task force report on antidepressant use in bipolar disorders. Am J Psychiatry 170(11):1249-1262. https://doi.org/ 10.1176/appi.ajp.2013.13020185

26. Di Nicola M, Mazza M, Panaccione I, Moccia L, Giuseppin G, Marano G, Grandinetti P, Camardese G, De Berardis D, Pompili M, Janiri L (2020) Sensitivity to climate and weather changes in euthymic bipolar subjects: association with suicide attempts. Front Psychiatry 11:95. https://doi.org/10.3389/fpsyt.2020.00095

27. Sani G, Perugi G, Tondo L (2017) Treatment of Bipolar Disorder in a Lifetime Perspective: Is Lithium Still the Best Choice? Clin Drug Investig 37(8):713-727. https://doi.org/10.1007/ s40261-017-0531-2

28. American Psychiatric Association (2000) Diagnostic and statistical manual of mental disorders 4th Edition. Text Revision (DSM-IV-TR 
29. Buoli M, Cesana BM, Barkin JL, Tacchini G, Altamura AC (2018) Validity of a clinical diagnosis of bipolar disorder among participants in a multicenter study using the Mini-International Neuropsychiatric Interview. Bipolar Disord 20(3):284. https://doi.org/ 10.1111/bdi.12635

30. Sheehan DV, Lecrubier Y, Sheehan KH, Amorim P, Janavs J, Weiller E, Hergueta T, Baker R, Dunbar GC (1998) The MiniInternational Neuropsychiatric Interview (M.I.N.I.): the development and validation of a structured diagnostic psychiatric interview for DSM-IV and ICD-10. J Clin Psychiatry 59:22-33

31. Vieta E, Pacchiarotti I, Valentí M, Berk L, Scott J, Colom F (2009) A critical update on psychological interventions for bipolar disorders. Curr Psychiatry Rep 11(6):494-502. https://doi.org/10.1007/ s11920-009-0075-0

32. Colom F, Vieta E, Suppes T (2015) Predominant polarity in bipolar disorders: refining or redefining diagnosis? Acta Psychiatr Scand 132(5):324-326. https://doi.org/10.1111/acps.12503

33. Raue PJ, Ghesquiere AR, Bruce ML (2014) Suicide risk in primary care: identification and management in older adults. Curr Psychiatry Rep 16(9):466. https://doi.org/10.1007/ s11920-014-0466-8

34. Buoli M, Cesana BM, Dell'Osso B, Fagiolini A, de Bartolomeis A, Bondi E, Maina G, Bellomo A, Altamura AC (2019) Genderrelated differences in patients with bipolar disorder: a nationwide study. CNS Spectr 24(6):589-596. https://doi.org/10.1017/S1092 852918001529

35. Finseth P, Morken G, Andreassen OA, Malt UF, Vaaler AE (2012) Risk factors related to lifetime suicide attempts in acutely admitted bipolar disorder inpatients. Bipolar Disord 14(7):727-734. https://doi.org/10.1111/bdi.12004

36. Karanti A, Kardell M, Joas E, Runeson B, Pålsson E, Landén M (2020) Characteristics of bipolar I and II disorder: a study of 8766 individuals. Bipolar Disord 22(4):392-400. https://doi.org/ 10.1111/bdi.12867

37. Almeida VF, Bezerra-Filho S, Studart-Bottó P, Léda-Rego G, Silva ITF, Kapczinski F (2020) History of suicide attempts in patients with bipolar disorder type I: socio-demographic and clinical factors, quality of life and functioning. Nord J Psychiatry 2:3

38. Altamura AC, Serati M, Buoli M (2015) Is duration of illness really influencing outcome in major psychoses? Nord J Psychiatry 69(6):403-417. https://doi.org/10.3109/08039488.2014.990919

39. Drancourt N, Etain B, Lajnef M, Henry C, Raust A, Cochet B, Mathieu F, Gard S, Mbailara K, Zanouy L, Kahn JP, Cohen RF, Wajsbrot-Elgrabli O, Leboyer M, Scott J, Bellivier F (2013)
Duration of untreated bipolar disorder: missed opportunities on the long road to optimal treatment. Acta Psychiatr Scand 127(2):136-144. https://doi.org/10.1111/j.1600-0447.2012. 01917.x

40. McElroy SL, Kotwal R, Kaneria R, Keck PE Jr (2006) Antidepressants and suicidal behavior in bipolar disorder. Bipolar Disord 8:596-617. https://doi.org/10.1111/j.1399-5618.2006.00348.x

41. Tondo L, Vázquez GH, Baldessarini RJ (2017) Depression and mania in bipolar disorder. Curr Neuropharmacol 15(3):353-358. https://doi.org/10.2174/1570159X14666160606210811

42. Vismara M, Grancini B, Cremaschi L, Oldani L, Arici C, de Carlo V, Miller S, Ketter TA, Altamura AC, Dell'Osso B (2018) Suicide attempts and clinical correlates in patients with bipolar I vs II disorder. Eur Psychiatry 52:113-115. https://doi.org/10.1016/j. eurpsy.2018.04.009

43. Goffin KC, Dell'Osso B, Miller S, Wang PW, Holtzman JN, Hooshmand F, Ketter TA (2016) Different characteristics associated with suicide attempts among bipolar I versus bipolar II disorder patients. J Psychiatr Res 76:94-100. https://doi.org/10. 1016/j.jpsychires.2016.02.006

44. Silva RAD, Mograbi DC, Camelo EVM, Santana CMT, LandeiraFernandez J, Cheniaux E (2017) Clinical correlates of loss of insight in bipolar depression. Trends Psychiatry Psychoth 39(4):264-269. https://doi.org/10.1590/2237-6089-2017-0007

45. Choudhury S, Avasthi A, Chakrabarti S (2020) Grover S (2021) A comparative study evaluating insight in different phase of illness among patients with bipolar disorder by using multiple scales. Nord J Psychiatry. https://doi.org/10.1080/08039488.2020.18710 68

46. Ayesa-Arriola R, Terán JMP, Moríñigo JDL, Rivero MC, SetiénSuero E, Al-Halabi S, Cuesta MJ, David AS, Crespo-Facorro B (2018) The dynamic relationship between insight and suicidal behavior in first episode psychosis patients over 3-year followup. Eur Neuropsychopharmacol 28(10):1161-1172. https://doi. org/10.1016/j.euroneuro.2018.05.005

47. Acosta FJ, Navarro S, Cabrera B, Ramallo-Fariña Y, Martínez N (2020) Painful insight vs. usable insight in schizophrenia. Do they have different influences on suicidal behavior? Schizophr Res 220:147-154. https://doi.org/10.1016/j.schres.2020.03.042

48. Joas E, Bäckman K, Karanti A, Sparding T, Colom F, Pålsson E, Landén M (2020) Psychoeducation for bipolar disorder and risk of recurrence and hospitalization - a within-individual analysis using registry data. Psychol Med 50(6):1043-1049. https://doi. org/10.1017/S0033291719001053

\title{
Authors and Affiliations
}

\begin{abstract}
Massimiliano Buoli ${ }^{1,2}$ (D) Bruno Mario Cesana ${ }^{3} \cdot$ Simone Bolognesi $^{4} \cdot$ Andrea Fagiolini $^{4} \cdot$ Umberto Albert $^{5}$. Gabriele Di Salvo $^{6}$. Giuseppe Maina ${ }^{6}$. Andrea de Bartolomeis ${ }^{7} \cdot$ Maurizio Pompili $^{8}$. Claudia Palumbo ${ }^{9}$. Emi Bondi ${ }^{9} \cdot{\text { Luca Steardo } \mathrm{Jr}^{10} \text {. Pasquale De Fazio }}^{10}$ - Mario Amore ${ }^{11}$. Mario Altamura ${ }^{12}$. Antonello Bellomo ${ }^{12}$. Alessandro Bertolino ${ }^{13}$. Marco Di Nicola ${ }^{14,15}$. Guido Di Sciascio ${ }^{16}$. Andrea Fiorillo ${ }^{17}$. Emilio Sacchetti ${ }^{18,19}$. Gabriele Sani ${ }^{14,15}$. Alberto Siracusano ${ }^{20,21}$ - Giorgio Di Lorenzo ${ }^{20,21}$. Alfonso Tortorella ${ }^{22}$ - A. Carlo Altamura ${ }^{1,2}$. Bernardo Dell'Osso ${ }^{23,24,25}$ on behalf of the ISBD Italian Chapter Epidemiologic Group
\end{abstract}

1 Department of Neurosciences and Mental Health, Fondazione IRCCS Ca'Granda Ospedale Maggiore Policlinico, Via F. Sforza 35, 20122 Milan, Italy

2 Department of Pathophysiology and Transplantation, University of Milan, Milan, Italy

3 Department of Clinical Sciences and Community Health, Unit of Medical Statistics, Biometry and Bioinformatics
"Giulio A. Maccacaro", Faculty of Medicine and Surgery, University of Milan, Milan, Italy

4 University of Siena School of Medicine, Siena, Tuscany, Italy

5 Department of Medicine, Surgery and Health Sciences, Department of Mental Health, UCO Clinica Psichiatrica, ASUGI-Azienda Sanitaria Universitaria Giuliano-Isontina, University of Trieste, Trieste, Italy 
6 San Luigi Gonzaga Hospital, University of Turin, Turin, Italy

7 Laboratory of Molecular Psychiatry and Translational Psychiatry, Unit of Treatment Resistant Psychosis, Section of Psychiatry, Department of Neuroscience, Reproductive Science and Odontostomatology, University School of Medicine of Napoli Federico II, Naples, Italy

8 Department of Neurosciences, Mental Health and Sensory Organs, Suicide Prevention Center, Sapienza University of Rome, Rome, Italy

9 Department of Psychiatry, Hospital Papa Giovanni XXIII, Bergamo, Italy

10 Psychiatric Unit, Department of Health Sciences, University Magna Graecia, Catanzaro, Italy

11 Department of Neuroscience, Rehabilitation, Ophthalmology, Genetics, Maternal and Child Health, Section of Psychiatry, IRCCS Ospedale Policlinico San Martino, University of Genoa, Genoa, Italy

12 Psychiatric Unit, Department of Clinical and Experimental Medicine, University of Foggia, Foggia, Italy

13 Department of Basic Medical Sciences, Neuroscience and Sense Organs, University of Bari, Bari, Italy

14 Department of Psychiatry, Fondazione Policlinico Universitario Agostino Gemelli IRCCS, Rome, Italy
15 Department of Neuroscience, Section of Psychiatry, Università Cattolica del Sacro Cuore, Rome, Italy

16 Department of Mental Health ASL, Bari, Italy

17 Department of Psychiatry, University of Campania "L. Vanvitelli", Naples, Italy

18 Department of Mental Health and Addiction Services, ASST Spedali Civili, Brescia, Italy

19 Department of Clinical and Experimental Sciences, University of Brescia, Brescia, Italy

20 Department of Systems Medicine, University of Rome Tor Vergata, Rome, Italy

21 Unit of Psychiatry and Clinical Psychology, Policlinico Tor Vergata Foundation, Rome, Italy

22 Department of Psychiatry, University of Perugia, Perugia, Italy

23 Department of Biomedical and Clinical Sciences "Luigi Sacco", Psychiatry Unit 2, ASST-Fatebenefratelli-Sacco, via G.B.Grassi 74, 20157 Milan, Italy

24 Department of Psychiatry and Behavioral Sciences, Stanford University, Stanford, CA, USA

25 CRC “Aldo Ravelli” for Neurotechnology and Experimental Brain Therapeutics, University of Milan, Milan, Italy 